\title{
Review
}

\section{Natural Health Products, Modulation of Immune Function and Prevention of Chronic Diseases}

\author{
Pierre S. Haddad ${ }^{1,2,5}$, Georges A. Azar ${ }^{3}$, Simon Groom ${ }^{4}$ and Michel Boivin ${ }^{1,5}$ \\ ${ }^{1}$ Fondation Lucie et André Chagnon, 2001 McGill College, Suite 1000, ${ }^{2}$ Department of Pharmacology and ${ }^{3}$ Department \\ of Microbiology and Immunology, Université de Montréal, 2900 Edouard-Montpetit, Montreal, ${ }^{4}$ Department of \\ Human Nutrition, Macdonald College, McGill University, Ste-Anne-de-Bellevue and ${ }^{5}$ Centre Hospitalier \\ de l'Université de Montréal, Hôpital St-Luc, 1058 St-Denis, Montreal, Quebec, Canada
}

\begin{abstract}
The immune system is increasingly found to be involved in the development of several chronic illnesses, for which allopathic medicine has provided limited tools for treatment and especially prevention. In that context, it appears worthwhile to target the immune system in order to modulate the risk of certain chronic illnesses. Meanwhile, natural health products (NHPs) are generating renewed interest, particularly in the prevention and treatment of several chronic diseases. Over 20 scientists from fields related to immune function and NHPs were thus convened to establish the state of knowledge on these subjects and to explore future research directions. This review summarizes the result of discussions held during the symposium. It thus seeks to be thought provoking rather than to comprehensively cover such broad areas of research. Notably, a brief overview of the immune system is presented, including potentially useful targets and strategies to keep it in an equilibrated state, in order to prevent certain disorders. The pertinence and limitations of targeting the immune system to prevent chronic diseases is also discussed. The paper then discusses the usefulness and limitations of current experimental tools available to study the immune modulating effects of NHPs. Finally, a concise review of some of the most studied NHPs showing promising immunomodulatory activity is given, and avenues for future research are described.
\end{abstract}

Keywords: NK cells - Cytokines - Microparticles - Probiotics - Natraprevention - Vitamins - n-3 fatty acids - Green tea - Echinacea - Ginseng

\section{Introduction}

This concise review presents an expanded summary of discussions held during a symposium entitled 'Maintenance of an efficient and equilibrated immune system through the novel use of natural health products' and that was the object of a recent meeting report (1). The symposium brought together between 20 and 30 scientists in disciplines ranging from herbalism, ethnobotany and phytochemistry, through to basic and clinical research in fields such as immunology, cancer and nutrition. It was held in Montreal, Canada, on September 23 and 24, 2004 under the auspices of the Lucie and André

For reprints and all correspondence: Pierre S. Haddad, Research Coordinator, Fondation Lucie et André Chagnon, 2001 McGill College Avenue, Montreal, Quebec, Canada H3A 1G1. Tel: +514-380-2001 ext. 1098; Fax: +514-3808434; E-mail: pierre.haddad@umontreal.ca
Chagnon Foundation, Canada's largest philanthropic organization. Participants were asked to discuss the relationship between the modulation of immune system functions and the prevention of chronic diseases, and to explore natural health products (NHPs) that may find novel and judicious use in this context. Other symposium details, including the list of participants, can be found in the published meeting report (1).

The complexity of the immune system is secondary only to that of the central nervous system although the immune system is older in evolutionary terms (2). Our immune system is often conceptualized as possessing two principal components: innate and adaptive immunity, which work in concert to defend the body against infection.

The innate system is ancestral and present in invertebrates as well as vertebrates. It is neither anticipatory (no memory) nor clonal and does not respond to environmental changes. The

(C) The Author (2005). Published by Oxford University Press. All rights reserved.

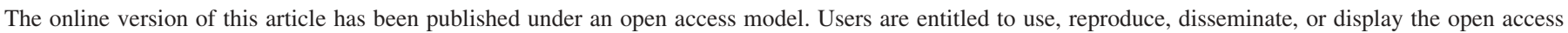

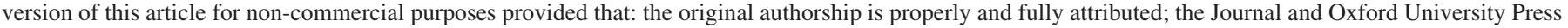

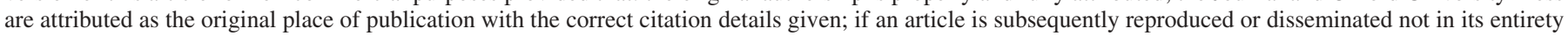
but only in part or as a derivative work this must be clearly indicated. For commercial re-use, please contact journals.permissions@oxfordjournals.org 
innate system reacts directly to a wide variety of microorganisms through receptors for highly conserved and essential microbial molecules, such as lipopolysaccharides present on the cell wall of Gram-negative bacteria and lipoteichoic acids present in Gram-positive bacteria. Indeed, the cells of the innate immune system represent the first line of defence in the immunosurveillance network. The primary cells involved in the identification and spontaneous lysis of offensive targets (virus-infected cells, tumor cells, bone marrow stem cells and embryonic cells) are natural killer (NK) cells, which have been the object of several ground breaking studies in the later part of the last century (3-8). These cells originate from the bone marrow, from which they travel in a unidirectional and almost exclusive way to the spleen; very few NK cells are found in lymph nodes or other secondary sites such as the gut-associated and bronchi-associated lymphatic tissue (3,9-15). Nonetheless, NK cells are lymphoid in morphology and need cells of the macrophage/monocyte lineage for the full expression of NK cell production or function. NK cells are numerically and functionally low in youth and old age, and maximal during the reproductive periods in mammals. Moreover, an inverse relationship exists between the rise and fall of NK cells and the incidence of tumor growth. This phenomenon is believed to be more than coincidental. The studies of Dussault and Miller (16-18) have elucidated some of the factors underlying this relationship. In elderly mice, bone marrow NK cell production and their capacity to bind onto offensive target cells are significantly reduced relative to that of the young adult mammal, thus attenuating any potential for tumor cell lysis. In contrast, very young mammals produce NK cells at a level comparable to that of young adults, but there exist NK-suppressive factors in the microenvironment of the spleen that prevent NK cells from lysing offensive targets. In humans, this corresponds to a time when pediatric leukemias and lymphomas are prevalent. This demonstrates, in part, the importance of NK cells and of the adaptive system in general for the maintenance of optimal immune function.

In contrast, the adaptive system, also termed specific immunity, is acquired through interactions with the environment. It is subject to induction, anticipation (immune memory) and clonal expansion. Adaptive immune responses are central to the body's ability to eliminate bacterial, viral and parasitic infections. Understanding these responses is the key to understanding the phenomena of allergy, autoimmunity, vaccination, cancer and organ graft rejection/acceptance. Adaptive immunity has been known for over a century and an abundant literature exists, which is fully reviewed in classical works such as those of Roitt and Delves (19) and Paul (20). The cells involved in adaptive responses are thymus ( $\mathrm{T}$ )-derived cytotoxic $\mathrm{T}$ lymphocytes and helper $\mathrm{T}$ lymphocytes (the latter existing in two subsets: Thl and Th2), bone (B) marrowderived lymphocytes and assorted accessory cells (dendritic cells, macrophages and stromal cells). Lymphoid tissue is distributed all over the body. Lymphocytes (along with several of their accessory cells) circulate to and through the spleen, lymph nodes, specialized lymphoid tissue in the gut (Peyer's Patches and appendix), bronchi and oropharynx (adenoids and tonsils). These 'secondary' sites serve as clonal generating stations for $\mathrm{T}$ and $\mathrm{B}$ lymphocytes, once the appropriate antigen (from bacterial, viral or parasitic sources) has been encountered. Thus, an army of identical and antigenspecific lymphocytes is uniquely directed at the offensive antigen, ensuring its elimination in normal animals, including humans. Cytotoxic T lymphocytes destroy virus-infected cells by making direct contact with the latter in order to induce cytolysis. Th1 cells, on the other hand, 'activate' the appropriate accessory cell, and it is the latter that then delivers the cytolytic blow. Th1 cells are the target of the AIDS virus, and when the vital Th1 cells are crippled throughout the body (advanced AIDS), opportunist infections ultimately kill the infected host (human or animal). Th2 lymphocytes activate B lymphocytes whose function is to produce an appropriate antibody against the offensive antigen, leading to its destruction and elimination.

The innate and adaptive systems are highly integrated and interdependent (21). In addition to being a requisite for adaptive immunity, the innate system is responsible for the early killing and clearance of infectious pathogens and the resolution of the inflammatory response. The most important means by which the immune system communicates internally and externally is through the use of cytokines, small soluble signaling molecules. Cytokines play a crucial role in the selection, initiation and modulation of an appropriate immune response. The signaling network of cytokines is characterized by its complexity (synergy and antagonism) and by its redundancy (parallelism) that ensure the speed and flexibility required for an effective immune response.

The immune system can give rise to several disorders when it is weakened or overactivated (Table 1). For instance, a defective adaptive immune response can lead to recurrent infection despite previous encounters with antigens, to lowered tolerance to self-organs and tissues leading to organ-specific autoimmunity, and to faulty recognition and elimination of transformed cells leading to cancer. However, an overactivated innate immune response can cause chronic infection because of inefficient clearing of pathogen or chronic inflammation due to an inefficient regulation or resolution of the inflammatory response. Chronic inflammation can lead to extensive non-specific destruction of neighboring tissue. In fact, inflammation and the immune system are intimately tied. In addition,

Table 1. Health effects of imbalances of the immune system

\begin{tabular}{ll}
\hline Immune system status & Attributable pathologies \\
\hline Weak & Prone to opportunistic infectious diseases \\
& Prone to cancer establishment and tumor escape \\
Overactivated & Chronic inflammation and autoimmunity \\
& (e.g. Type 1 diabetes) \\
& Heart disease, cancer (e.g. lymphoid) \\
& Skin disease, allergies and asthma \\
& Joint and tissue destruction \\
\hline
\end{tabular}


inflammation is increasingly found to be involved in the development of several chronic diseases such as arteriosclerosis, diabetes, neurodegenerative diseases and even cancer. Immune dysfunction has also been linked to conditions such as chronic pain, anxiety and depression, albeit sometimes as a consequence rather than a cause, and may be involved in other disease processes in a manner that is currently not fully understood (22). Indeed, its diverse influence upon health may be in part due to its evolution as a defence mechanism and in part due to its origins, possibly as a sensory organ (23).

\section{Is the Immune System a Good Target to Aim at In Order to Prevent Chronic Disease? Yes, But...}

A first question to address is whether the immune system is a good target to select in the fight to prevent chronic diseases. Consensus is generally positive with some important reservations being brought forward. In fact, it is accepted that the immune system represents our arsenal to combat infection and disease. As mentioned, an underactivated immune system increases risks of opportunistic infection and uncontrolled neoplastic tissue growth, while an overactivated immune system leads to many afflictions, including inflammation, allergy and autoimmunity. Hence, an unchecked and unbalanced immune system hampers good health and quality of life. This explains the consensus 'Yes' given as an answer by the experts regarding the pertinence of targeting the immune system to prevent chronic disease.

However, it must be noted that the immune system carries out its important defensive function in intimate and coordinated interaction with the nervous and endocrine systems $(24,25)$. The innate complexity of the immune system and of its communication tool, the cytokines, is thus further complicated by these interactions with the nervous and endocrine systems. Some concern also arises when considering that targeting the immune system may be too reductionist an approach, particularly when dealing with complex pathologies like cancer. These considerations form the basis of the 'but...' part of the answer given in the title to this subsection.

\section{Promising Research Avenues and Markers}

It is important to consider that invertebrate species lack adaptive immunity but are clearly able to deal effectively with infections. It is also interesting to note that these organisms do not appear to develop cancer or autoimmune disease (at least not in any readily recognizable form), but they do demonstrate senescence (26-28). Therefore, the apparent absence of these age-related diseases in invertebrates could support an evolutionary argument to focus disease prevention upon maintenance of efficient and equilibrated innate immunity.

If this line of reasoning is correct, then the immune cells of greatest interest are ones of the $\mathrm{NK}$ cell lineage described above. These immune cells are present in invertebrate and vertebrate species and serve as a link between innate and adaptive immunity in vertebrates, as mentioned (25). Indeed, NK cell function has been identified as a reliable measure of immunotoxicity for use in pharmaceutical safety testing (29) and could perhaps provide a means to monitor immune system equilibrium.

Another important point to consider relates to the problem of markers for immune system function. It is difficult to reach a consensus on the appropriate markers to use in order to monitor the maintenance of a healthy immune system, primarily because biological heterogeneity precludes readily identifiable thresholds for concern in the prevention of chronic disease. However, there exist potential novel avenues to explore, including the use of NK cell activity, as mentioned above, or the use of a constellation of markers, of which cytokines and cytokine receptors would be a major part. Much has been written about the validity and validation of biomarkers for health monitoring (30). While it is beyond the scope of this paper to discuss these issues at length, it is worth highlighting some general considerations. Firstly, biomarkers must be relevant to the question being asked and practical to use in the desired setting since advances in analytical sensitivity can now provide detection limits at concentrations often below those that have biological importance (31). Secondly, it is generally easier to define thresholds for intervention (i.e. when a disease requires treatment) than for early detection or prevention (i.e. before onset of the disease). Indeed, thresholds for disease prevention require a good definition of what constitutes the "normal' condition. However, biological heterogeneity and the redundancy present within the immune system makes the establishment of precise 'normal ranges' especially difficult. Therefore, although NK cell activity and cytokine assays can be used as reliable measures for treatment intervention $(32,33)$ they have yet to be shown to be practical biomarkers for defining a threshold for the early detection of chronic illnesses.

Finally, one interesting alternative to conventional immune system biomarkers is the presence and quality of microparticles present in the blood. Such microparticles, including exosomes, originate from several cells, including some prominent immune cells, and may represent a novel type of intercellular signaling mechanism $(34,35)$. Hence, research into the development of novel and pertinent biomarkers will certainly contribute to finding ways to modulate the immune system and prevent certain chronic diseases.

\section{Tools to Study the Immune System and NHPs}

In this section we briefly review several experimental models and approaches that have been used to study immunomodulatory NHPs. Table 2 summarizes the advantages and limitations of each modality. Human clinical studies remain the gold standard upon which scientists and health care professionals can rely to determine the usefulness and efficacy of a given NHP. Nonetheless, animal models, in vitro bioassays, and 
Table 2. Tools to study NHPs as related to the immune system

\begin{tabular}{|c|c|c|}
\hline Experimental models/tools & Pros & Cons \\
\hline \multirow[t]{3}{*}{$\begin{array}{l}\text { In vitro measurement on } \\
\text { cell culture }\end{array}$} & $\begin{array}{l}\text { Can target specific effects of the studied product on } \\
\text { specific cell types }\end{array}$ & $\begin{array}{l}\text { Simplistic model, systemic effects not taken into } \\
\text { consideration }\end{array}$ \\
\hline & $\begin{array}{l}\text { Very helpful for investigating cellular and molecular } \\
\text { mechanisms }\end{array}$ & NHP administration generally not physiological \\
\hline & $\begin{array}{l}\text { Large number of very well characterized systems with } \\
\text { efficient markers of activation/inhibition }\end{array}$ & \\
\hline & Can be used in fundamental research as well as clinical trials & \\
\hline \multirow[t]{2}{*}{ Animal models } & Mouse has a very well characterized genome & $\begin{array}{l}\text { Despite high similarities with man, uncertainty whether } \\
\text { mice and men react the same way }\end{array}$ \\
\hline & Complete living organism & $\begin{array}{l}\text { Difficulty in measuring environmental components } \\
\text { on a mouse }\end{array}$ \\
\hline Clinical trials & Direct and systemic effects measured on health & Improper administration/standardization of NHPs \\
\hline \multirow[t]{2}{*}{ Epidemiological studies } & Large-scale studies on the population & $\begin{array}{l}\text { Challenge in scientifically measuring dietary exposure in } \\
\text { the population }\end{array}$ \\
\hline & $\begin{array}{l}\text { Can include both the environmental and germ } \\
\text { line components of disease }\end{array}$ & Large cohorts needed for significant conclusions \\
\hline
\end{tabular}

modern proteomic and genomic technologies can be most helpful in delineating the mode of action of NHPs. Finally, epidemiological studies bring a wealth of information on the influence of genetic (germ line) and environmental factors on health outcomes in the general population and pertinent subgroups.

In addition, it is generally recognized that a great effort should be placed on the standardization of methods used to study immune modulation by NHPs. In terms of herbals, this also includes a crucial component of standardization of the herbal preparations themselves. As mentioned in Table 2 above, the greatest inconsistencies of clinical research related to immunomodulatory NHPs are caused in major part by the lack of quality control of the source materials used (36). The US agency NCCAM came to a similar conclusion after its first 5 years of functioning and is now focusing on more preclinical studies to prepare better clinical studies, notably with herbal products (http://nccam.nih.gov/about/plans/2005/index.htm).

\section{NHPs having Immunomodulatory Activity}

During the last century, modern medicine has contributed major advancements to sanitation and public health initiatives and discoveries like antibiotics and vaccination. These efficiently hindered the progression of infectious diseases through the population. In fact, modern medicine has succeeded best in treating acute illnesses. It is in the realm of chronic diseases that modern medicine and drugs have been more disappointing and that NHPs have elicited resurgent interest. In this section, we review the evidence for the immunomodulatory action of several NHPs, including probiotics, products of animal origin (principally milk and thymic extracts), nutritional factors (especially vitamins, minerals and fatty acids) and herbal products. Table 3 summarizes the strongest evidence brought forward for some of the most promising NHPs. Readers are also oriented to recent reviews $(37,38)$ for complementary information.

The gastrointestinal (GI) tract and the skin epidermis are the major barriers humans possess to confront the external environment. Both are responsible for maintaining systemic integrity and use lymph nodes as efficient immune checkpoints. The GI tract distinguishes itself by holding the greatest number of lymph nodes, and also by being the most intricate and complex immune organ. Probiotics are live bacteria that colonize the GI tract. They have received a lot of research attention, particularly in clinical studies in children and the elderly (39-42). Indeed, they positively affect general health going from the development of the immune system in infants right after birth to the enhancement of general immunity in the elderly (critically exposed to immunosenescence). Probiotics offer much promise because they appear not only to help with the maturation of the visceral immune system but also to equilibrate the body's defence mechanisms. In that sense, they act as true immunomodulating agents, enhancing immunity when it is weakened or developing, and buffering exaggerated reactions (e.g. allergies and inflammatory bowel disease). They also represent the only NHP category that research has shown to have well established curing 
Table 3. Promising NHPs exhibiting modulatory effects on the immune system

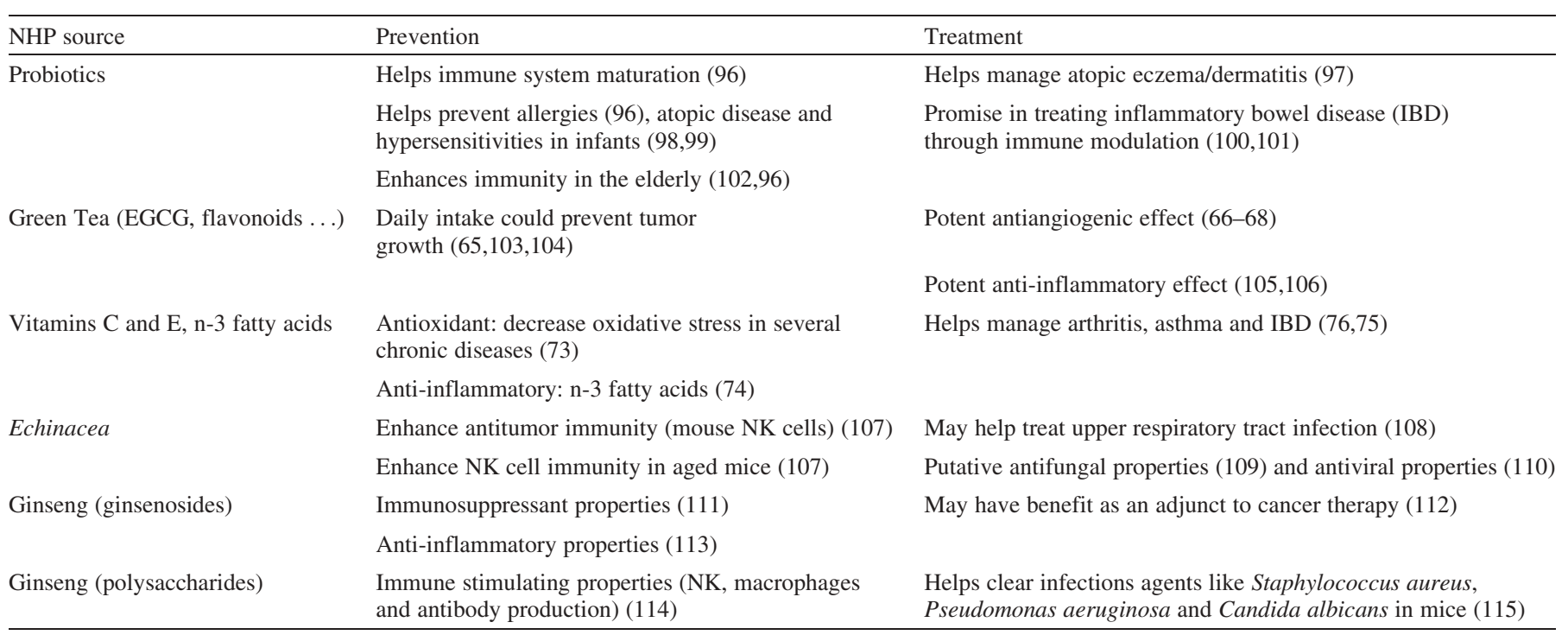

as well as preventive properties. Probiotics exert their actions principally by

1. Improving the intestinal immunologic barrier function through spatial exclusion of other pathogenic microbial that could otherwise colonize the gut $(43,44)$.

2. Restoring normal intestinal permeability (45) in the face of inflammatory or allergic diseases by still illdefined mechanisms that include cell wall and DNA components playing the role of immunomodulatory products (46) and by lowering the production of proinflammatory cytokines $(47,48)$.

3. Synthesizing vitamins (folic acid, biotin and other group $\mathrm{B}$ vitamins, vitamin $\mathrm{K}$ and so on) (116).

Suggestions have been made that probiotics may absorb heavy metals (49-51) and thus help their elimination through the feces. Probiotics may also promote the production of enzymes that help decrease the severity of certain food intolerances/ allergies (52). However, these actions have not been fully documented.

Data on milk peptides, bovine colostrum and thymic extracts are less convincing in terms of immune modulation, most of the research having been done in cellular models in vitro and showing contradicting results (53-64). Several peptides released from enzymatic hydrolysis of milk proteins were reported to modulate immune functions such as phagocytosis, lymphocyte proliferation and cytokine production. The type of enzymatic treatment has an influence on the immunomodulatory functions of peptides generated from milk proteins and, without standardized procedures, it is difficult to drawn conclusions from those studies. Further research, especially clinical trials, will be required to identify the impact of those products on the immune system in humans.

However, stronger evidence was presented to support the usefulness of a number of micronutrients to prevent certain chronic illnesses. A new term coined 'nutraprevention' is applied to the use of empirical combinations of foods, spices and other food-grade herbals in the fight against cancer (65). So far, this approach is based on epidemiological studies clearly showing relationships between cancer prevalence and food consumption in different populations around the world. Moreover, research is now showing potent antiangiogenic activity for polyphenolic components of green tea (66-68); angiogenesis being the process by which growing tumors promote the development of new blood vessels to ensure their survival. Several plant constituents, including soy isoflavones $(69,70)$ and compounds in cruciferous vegetables $(71,72)$, are also known to modulate enzymes involved in xenobiotic biotransformation, namely, the activation or detoxification of 'foreign', pro-carcinogenic chemicals. Vitamin $\mathrm{C}$ has been clearly linked to the modulation of immune function, particularly in the context of novel research showing improved cognitive status in patients with neurodegenerative disorders (73), which are increasingly shown to involve an immune dysfunction component. Similarly, polyunsaturated fatty acids, in particular the now famous $\omega-3$ fatty acids, have been used successfully in the management and prevention of several inflammatory and allergic diseases (74-76). However, clinical research on lipids has yielded inconsistent results concerning their potential to modulate immune system function. This state of affairs is related to poor study design and to the great variability in immune cells selected and methods used to assess immune function.

Intake of green tea, Brassica vegetables (e.g. broccoli, cabbage and others) and soy foods has been shown to be associated with lower risk of several cancers in epidemiologic studies [reviewed in (77-82)]. Furthermore, data from experimental studies suggest that green tea and its constituents, such as isoflavones, may modulate markers of inflammation and immune function (83-87). A limited number of herbal products also show promise in the realm of immune modulation. 
It is notably the case with Echinacea that has received significant scientific attention in the past two decades, particularly in studies on upper respiratory tract infections $(36,88,89)$. Among its many immune modulating activities reported, activation of macrophages has been demonstrated most convincingly. However, novel mechanisms of action include effects on $\mathrm{B}$ and $\mathrm{T}$ lymphocytes as well as NK cells $(90,91)$. In particular, Currier and Miller (90) observed that upon incorporating Echinacea in the daily diet of elderly mice for only 14 days NK cell production in the bone marrow, as well as the number of mature functional NK cells reaching the spleen, increased to levels found in young adults (92). Brousseau and Miller (93) have also revealed that daily dietary intake of Echinacea throughout life, beginning in youth, increased the number of individuals reaching old age to $74 \%$ as opposed to $46 \%$ in control animals. Thus, any herbal treatment that would augment NK cells would clearly be worthy of investigation for its therapeutic/ prophylactic potential, especially in the realm of immune modulation.

Ginseng is the other herbal that shows much promise as an immune modulating NHP. Indeed, it appears to have both immunostimulant and immunosuppressant activities, which would lend credence to the view that ginseng is an 'adaptogenic' NHP. Immunostimulant activities have been attributed to polysaccharide fractions, notably acting on both macrophages and B lymphocytes $(94,95)$. However, ginsenosides display immunosuppressant activity in vitro by inhibiting cytokine release in activated macrophages (I. Lemaire, unpublished results). Hence, further research is warranted on ginseng and other adaptogenic herbals to define their potential use in preventing chronic diseases related to immune dysfunction.

\section{Summary and Conclusion}

Dysfunction of the immune system is clearly implicated in the development of several chronic diseases. Hence, attempting to maintain an efficient and equilibrated immune system is a valid approach to prevent certain chronic illnesses. However, this approach is limited by the great complexity of the immune system and its close interactions with the nervous and endocrine functions. This is further hampered by the difficulty in identifying reliable and convenient analytical tools to assess immune function and its modulation. In that context, interesting areas for future research include NK cells, constellation of cytokine markers and receptors and assessment of blood-borne microparticles. Despite these limitations, research on NHPs has shown that certain products offer novel avenues to modulate the immune system and help prevent chronic diseases. The most promising ones are probiotics, nutraprevention (combinations of biologically-active fruits, vegetables and spices) and so-called adaptogenic plants (e.g. echinacea and ginseng). Notwithstanding these encouraging results, future research efforts with NHPs will need to address the important issues of standardization in both product quality and research methodology. Among areas to favor in the research agenda on NHPs and immune modulation, this review highlights the following needs: (i) studies on the interaction between NHPs and immune cells, particularly the influence of NHPs on the innate immune system; (ii) epidemiological studies and clinical studies with NHPs in chronic illnesses where immune dysfunction may play a role. Finally, social/economic impact of NHPs in health care must also be considered.

\section{Acknowledgements}

This review is based on discussions held in September 2004 during a 2 day symposium organized and funded by the Lucie et André Chagnon Foundation in Montreal, Canada. The symposium is the object of a short meeting report in $e C A M(1)$. The authors express their gratitude to all participants for valuable comments and suggestions. Special thanks go to Yvan Boutin (Lévis-Lauzon College, Lévis, Canada), Edwin Cooper (UCLA, Los Angeles, CA, USA), Johanna Lampe (Fred Hutchison Cancer Research Center, Seattle, WA, USA), Sandra Miller (McGill University, Montreal, Canada) and Denis Roy (Laval University, Quebec City, Canada). Ms Geneviève Côté and Geneviève Beauchamp are heartfully thanked for devoting their time and innovative ideas to make the symposium organization such a success. We gratefully acknowledge the expert secretarial help of Ms Laure Pinto.

\section{References}

1. Haddad PS, Beauchamp G, Côté G, Boivin M. Maintenance of an efficient, equilibrated immune system through the novel use of natural health products: synopsis of a symposium. eCAM 2005;2:237-8.

2. Cooper E. Commentary on CAM and NK cells by Kazuyoshi Takeda and Ko Okumura. eCAM 2004;1:29-34.

3. Keissling R, Klein E, Pross H, Wigzell H. Natural killer cells in the mouse. II. Cytotoxic cells with specificity for mouse Moloney leukemia cells: characteristics of the killer cell. Eur J Immunol 1975;5:117-21.

4. Herberman RB, Nunn ME, Larvin DH. Natural cytotoxic reactivity of mouse lymphoid cells against syngeneic and allogeneic tumors. I. Distribution of reactivity and specificity. Int J Cancer 1975;16:216-29.

5. Miller SC. Genetically determined resistance to foreign bone marrow transplantation in mice: characterization of the effector cells. J Immunol 1983;131:92-7.

6. Hackett J, Tutt M, Lipscomb M, Bennett M, Koo G, Kumar V. Origin and differentiation of natural killer cells. II. Functional and morphologic studies of purified NK 1.1+ cells. J Immunol 1986;136:3124-31.

7. Krishnaraj R. Immunosenescence of human NK cells: effects on tumor target recognition, lethal hit and interferon sensitivity. Immunol Lett 1992;34:79-84.

8. Kutza J, Murasko DM. Effects of aging on natural killer cell activity and activation by interleukin-2 and IFN-a. Cell Immunol 1994;155:195-204.

9. Haller O, Wigzell H. Suppression of natural killer cell activity with radioactive strontium: effector cells are marrow dependent. J Immunol 1977;118:1503-6.

10. Seaman WE, Blackman MA, Gindhart TD, Roubinian JR, Loeb JM, Talal N. Estradiol reduces natural killer cells in mice. J Immunol 1978;121:2193-8.

11. Riccardi C, Barlozzari T, Santoni A, Herberman RB, Cesarini C. Transfer to cyclophosphamide-treated mice of natural killer (NK) cells and in vivo natural reactivity against tumors. J Immunol 1981;126:1284-7.

12. Koo GC, Cayre Y, Mittl LR. Comparative study of splenic natural killer cells and prothymocytes. Cell Immunol 1981;62:164-71.

13. Koo GC, Manyak CL. Generation of cytotoxic cells from murine bone marrow by human recombinant IL-2. J Immunol 1986;137:1751-6.

14. Kalland T. Interleukin 3 is a major negative regulator of the generation of natural killer cells from mouse bone marrow precursors. J Immunol 1986;137:2268-71. 
15. Pollack SB, Rosse C. The primary role of murine bone marrow in the production of natural killer cells. J Immunol 1987;139:2149-56.

16. Dussault I, Miller SC. Decline in natural killer cell-mediated immunosurveillance in aged mice- a consequence of reduced cell production and tumor binding capacity. Mech Ageing Dev 1994;75:115-29.

17. Dussault I, Miller SC. The effectiveness of immunotherapy in aged leukemic mice. Gerontology 1995;41:195-204.

18. Dussault I, Miller SC. Effect on leukemia cell numbers of in vivo administration of immunotherapeutic agents is age-dependent. Oncology 1996;53:241-6

19. Roitt IM, Delves PJ (eds). Encyclopedia of Immunology, 3rd edition. London/San DiegoAcademic Press, 1992.

20. Paul WE (ed). Fundamental Immunology, 4th edition. Philadelphia: Lippincott Williams \& Wilkins Publishers, 1998.

21. Hoebe K, Janssen E, Beutler B. The interface between innate and adaptive immunity. Nat Immunol 2004;5:971-4.

22. Ewald PW. Plague time: how stealth infections cause cancers, heart disease and other deadly ailments. New York: The Free Press, 2002, 282.

23. Blalock JE. The immune system as a sensory organ. J Immunol 1984;132:1067-70

24. Haddad JJ, Saade NE, Safieh-Garabedian B. Cytokines and neuroimmune-endocrine interactions: a role for the hypothalamic-pituitaryadrenal revolving axis. J Neuroimmunol 2002;133:1-19.

25. Takeda K, Okumura K. CAM and NK cells. eCAM 2004;1:17-27.

26. Flatt T. Assessing natural variation in genes affecting Drosophila lifespan. Mech Ageing Dev 2004;125:155-9.

27. Luo Y. Long-lived worms and aging. Redox Rep 2004;9:65-9.

28. Singh K. Mitochondrial dysfunction is a common phenotype in aging and cancer. Ann NY Acad Sci 2004;1019:260-4.

29. USFDA. Immunotoxicology evaluation of investigational new drugs, Guidance for Industry Document issued by the Center for Drug Evaluation and Research.35.

30. World Health Organization. Environmental Health Criteria 222: Biomarkers In Risk Assessment: Validity And Validation, Report published under the joint sponsorship of the United Nations Environment Program, the International Labor Organization, and the World Health Organization, and produced within the framework of the InterOrganization Program for the Sound Management of Chemicals.

31. Pritzker KPH. Cancer biomarkers: easier said than done. Clin Chem 2002;48:1147-50.

32. Kelley DS, Taylor PC, Nelson GJ, Schmidt PC, Mackey BE, Kyle D. Effects of dietary arachidonic acid on human immune response. Lipids 1997:32:449-56.

33. Kelley DS, Taylor PC, Nelson GJ, Mackey BE. Dietary docosahexaenoic acid and immunocompetence in young healthy men. Lipids 1998;33: $559-66$.

34. Denzer K, Kleijmeer MJ, Heijnen HF, Stoorvogel W, Geuze HJ. Exosome: from internal vesicle of the multivesicular body to intercellular signalling device. J Cell Sci 2000;113:3365-74.

35. Freyssinet JM. Cellular microparticles: what are they bad or good for? J Thromb Haemost 2003;1:1655-62.

36. Goel V, Lovlin R, Barton R, Lyon MR, Bauer R, Lee TD, et al. Efficacy of a standardized Echinacea preparation (Echinilin) for the treatment of the common cold: a randomized, doubled-blind, placebo-controlled trial. J Clin Pharm Ther 2004;29:75-83.

37. Plaeger SF. Clinical immunology and traditional herbal medicines. Clin Diagn Lab Immunol 2003;10:337-8.

38. Patwardhan B, Gautam M. Botanical immuodrugs: scope and opportunities. Drug Discov Today 2005;10:495-502.

39. Shi HN, Walker A. Bacterial colonization and the development of intestinal defence. Can J Gastroenterol 2004;18:493-500.

40. Marteau P, Seksik P, Lepage P, Dore J. Cellular and physiological effects of probiotics and prebiotics. Mini Rev Med Chem 2004:4:889-96.

41. Brown AC, Valiere A. Probiotics and medical nutrition therapy. Nutr Clin Care 2004;7:56-68.

42. Bruzzese E, Canani RB, De Marco G, Guarino A. Microflora in inflammatory bowel diseases: a pediatric perspective. J Clin Gastroenterol 2004;38:S91-3.

43. Resta-Lenert S, Barrett KE. Live probiotics protect intestinal epithelial cells from the effects of infection with enteroinvasive Escherichia coli (EIEC). Gut 2003;52:988-97.

44. Jenkins B, Holsten S, Bengmark S, Martindale R. Probiotics: a practical review of their role in specific clinical scenarios. Nutr Clin Pract 2005;20:262-70.
45. Madsen K, Cornish A, Soper P, McKaigney C, Jijon H, Yachimec C, et al. Probiotic bacteria enhance murine and human intestinal epithelial barrier function. Gastroenterology 2001;121:580-91.

46. Jijon H, Backer J, Diaz H, Yeung H, Thiel D, McKaigney C, et al. DNA from probiotic bacteria modulates murine and human epithelial and immune function. Gastroenterology 2004;126:1358-73.

47. Madsen KL, Doyle JS, Jewell LD, Tavernini MM, Fedorak RN. Lactobacillus species prevents colitis in interleukin 10 gene-deficient mice. Gastroenterology 1999;116:1107-14.

48. Lammers KM, Helwig U, Swennen E, Rizzello F, Venturi A, Caramelli E, et al. Effect of probiotic strains on interleukin 8 production by HT29/19A cells. Am J Gastroenterol 2002;97:1182-6.

49. Summers AO, Wireman J, Vimy MJ, Lorscheider FL, Marshall B, Levy SB, et al. Mercury released from dental "silver" fillings provokes an increase in mercury- and antibiotic-resistant bacteria in oral and intestinal floras of primates. Antimicrob Agents Chemother 1993;37: $825-34$

50. Lorscheider FL, Vimy MJ, Summers AO, Zwiers H. The dental amalgam mercury controversy - inorganic mercury and the CNS; genetic linkage of mercury and antibiotic resistances in intestinal bacteria. Toxicology 1995;97:19-22.

51. Brudnak MA. Probiotics as an adjuvant to detoxification protocols. Med Hypotheses 2002;58:382-5.

52. de Vrese M, Stegelmann A, Richter B, Fenselau S, Laue C, Schrezenmeir J. Probiotics-compensation for lactase insufficiency. Am J Clin Nutr 2001;73:421S-9S.

53. Migliore-Samour D, Floc'h F, Jolles P. Biologically active casein peptides implicated in immunomodulation. J Dairy Res 1989;56: $357-62$.

54. Torre PM, Oliver SP. Supression of mitogenic response of peripheral blood mononuclear cells by bovine mammary secretions. J Dairy Sci 1989;72:219-27.

55. Fiat AM, Migliore-Samour D, Jolles P, Drouet L, Bal dit Sollier C, Caen J. Biologically active peptides from milk proteins with emphasis on two examples concerning antithrombotic and immunomodulating activities. J Dairy Sci 1993;76:301-10.

56. Schlimme E, Meisel H. Bioactive peptides derived from milk proteins. Structural, physiological and analytical aspects. Nahrung 1995;39:1-20.

57. Lahov E, Regelson W. Antibacterial and immunostimulating, caseinderived susbstances from milk: casecidin, isracidin peptides. Food Chem Toxicol 1996;34:131-45.

58. Cross ML, Gill HS. Immunomodulatory properties of milk. Br J Nutr 2000;84:81.

59. Shah NP. Effects of milk-derived bioactives: an overview. $\mathrm{Br} J$ Nutr 2000;84:S3-10

60. Low PP, Rutherfurd KJ, Gill HS, Cross ML. Effect of dietary whey protein concentrate on primary and secondary antibody responses in immunized BALB/c mice. Int Immunopharmacol 2003;3:393-401.

61. Legrand D, Elass E, Pierce A, Mazurier J. Lactoferrin and host defence: an overview of its immuno-modulating and anti-inflammatory properties. Biometals 2004;17:225-9.

62. Li EW, Mine Y. Immunoenhancing effects of bovine glycomacropeptide and its derivatives on the proliferative response and phogocytic activities of human macrophagelike cells, U937. J Agric Food Chem 2004;52: $2704-8$

63. Marshall K. Therapeutic applications of whey protein. Altern Med Rev 2004:9:136-56

64. Mercier A, Gauthier S, Fliss I. Immunomodulating effects of whey proteins and their enzymatic digests. Int Dairy J 2004;14:175.

65. Beliveau R, Gingras D. Green tea: prevention and treatment of cancer by nutraceuticals. Lancet 2004;364:1021-2.

66. Lamy S, Gingras D, Beliveau R. Green tea catechins inhibit vascular endothelial growth factor receptor phosphorylation. Cancer Res 2002;62:381-5

67. Cao Y, Cao R. Angiogenesis inhibited by drinking tea. Nature 1999; 398:381.

68. Cao Y, Cao R, Brakenhielm E. Antiangiogenic mechanisms of dietderived polyphenols. J Nutr Biochem 2002;13:380-90.

69. Kishida T, Beppu M, Nashiki K, Izumi T, Ebihara K. Effect of dietary soy isoflavone aglycones on the urinary 16alpha-to-2-hydroxyestrone ratio in C3H/HeJ mice. Nutr Cancer 2000;38:209-14.

70. Chan HY, Leung LK. A potential protective mechanism of soya isoflavones against 7,12-dimethylbenz[a]anthracene tumour initiation. $\mathrm{Br} \mathrm{J}$ Nutr 2003;90:457-65. 
71. Gill CI, Haldar S, Porter S, Matthews S, Sullivan S, Coulter J, et al. The effect of cruciferous and leguminous sprouts on genotoxicity, in vitro and in vivo. Cancer Epidemiol Biomarkers Prev 2004;13:1199-205.

72. Zhang Y. Cancer-preventive isothiocyanates: measurement of human exposure and mechanism of action. Mutat Res 2004;555:173-90.

73. Martin A. Antioxidant vitamins E and C and risk of Alzheimer's disease. Nutr Rev 2003;61:69-73.

74. Kelley DS. Modulation of human immune and inflammatory responses by dietary fatty acids. Nutrition 2001;17:669-73.

75. Simopoulos AP. Omega-3 fatty acids in inflammation and autoimmune diseases. J Am Coll Nutr 2002;21:495-505.

76. Endres S, Lorenz R. Loeschke. Lipid treatment of inflammatory bowel disease. Curr Opin Clin Nutr Metab Care 1999;2:117-20.

77. Murillo G, Mehta RG. Cruciferous vegetables and cancer prevention. Nutr Cancer 2001;41:17-28.

78. Kristal AR, Lampe JW. Brassica vegetables and prostate cancer risk: a review of the epidemiological evidence. Nutr Cancer 2002;42:1-9.

79. Le Marchand L. Cancer preventive effects of flavonoids. Biomed Pharmacother 2002;56:296-301.

80. Sarkar FH, Li Y. Soy isoflavones and cancer prevention. Cancer Invest 2003;21:744-57.

81. Limer JL, Speirs V. Phyto-oestrogens and breast cancer chemoprevention. Breast Cancer Res 2004;6:119-27.

82. Park OJ, Surh YJ. Chemopreventive potential of epigallocatechin gallate and genistein: evidence from epidemiological and laboratory studies. Toxicol Lett 2004;150:43-56.

83. Paradkar PN, Blum PS, Berhow MA, Baumann H, Kuo SM. Dietary isoflavones suppress endotoxin-induced inflammatory reaction in liver and intestine. Cancer Lett 2004;215:21-8.

84. Verdrengh M, Jonsson IM, Holmdahl R, Tarkowski A. Genistein as an anti-inflammatory agent. Inflamm Res 2003;52:341-6.

85. Surh YJ, Chun KS, Cha HH, Han SS, Keum YS, Park KK, et al. Molecular mechanisms underlying chemopreventive activities of antiinflammatory phytochemicals: down-regulation of COX-2 and iNOS through suppression of NF-kappa B activation. Mutat Res 2001;480: 243-68.

86. Katiyar SK, Challa A, McCormick TS, Cooper KD, Mukhtar H. Prevention of UVB-induced immunosuppression in mice by the green tea polyphenol (-)-epigallocatechin-3-gallate may be associated with alterations in IL-10 and IL-12 production. Carcinogenesis 1999;20: 2117-24.

87. Jenkins DJ, Kendall CW, Connelly PW, Jackson CJ, Parker T, Faulkner D, et al. Effects of high- and low-isoflavone (phytoestrogen) soy foods on inflammatory biomarkers and proinflammatory cytokines in middle-aged men and women. Metabolism 2002;51:919-24.

88. Block KI, Mead MN. Immune system effects of Echinacea, ginseng and astragalus: a review. Integr Cancer Ther 2003;2:247-67.

89. Barrett B. Medicinal properties of Echinacea: a critical review. Phytomedicine 2003;10:66-86.

90. Currier NL, Miller SC. Natural killer cells from aging mice treated with extracts from Echinacea purpurea are quantitatively and functionally rejuvenated. Exp Gerontol 2000;35:627-39.

91. Currier NL, Miller SC. Echinacea purpurea and melatonin augment natural-killer cells in leukemic mice and prolong life span. J Altern Complement Med 2001;7:241-51.

92. Sun LZ-Y, Currier NL, Miller SC. The American coneflower: a prophylactic role involving nonspecific immunity. J Altern Complement Med 1999;5:437-46.

93. Brousseau M, Miller SC. Enhancement of natural killer cells and increased survival of aging mice fed daily Echinacea root extract from youth. Biogerontology 2005; 6: 157-163.

94. Wang M, Guilbert LJ, Ling L, Li J, Wu Y, Xu S, et al. Immunomodulating activity of CVT-E002, a proprietary extract from North American ginseng (Panax quinquefolium). J Pharm Pharmacol 2001;53:1515-23.

95. Assinewe VA, Amason JT, Aubry A, Mullin J, Lemaire I. Extractable polysaccharides of Panax quinquefolius L. (North American ginseng) root stimulate TNF alpha production by alveolar macrophages. Phytomedicine 2002;9:398-404.

96. Cross ML. Immunoregulation by probiotic lactobacilli: pro-Th1 signals and their relevance to human health. Clin Appl Immunol Rev 2002;3: 115-25.

97. Viljanen M, Savilahti E, Haahtela T, Juntunen-Backman K, Korpela R, Poussa T, et al. Probiotics in the treatment of atopic eczema/dermatitis syndrome in infants: a double-blind placebo-controlled trial. Allergy 2005;60:494-500.

98. Majamaa H, Isolauri E. Probiotics: a novel approach in the management of food allergy. J Allergy Clin Immunol 1997;99:179-85.

99. Ogden NS, Bielory L. Probiotics: a complementary approach in the treatment and prevention of pediatric atopic disease. Curr Opin Allergy Clin Immunol 2005;5:179-84.

100. Fedorak RN, Madsen KL. Probiotics and the management of inflammatory bowel disease. Inflamm Bowel Dis 2004;10:286-99.

101. Kanauchi O, Matsumoto Y, Matsumura M, Fukuoka M, Bamba T. The beneficial effects of microflora, especially obligate anaerobes, and their products on the colonic environment in inflammatory bowel disease. Curr Pharm Des 2005;11:1047-53.

102. Gill HS, Rutherfurd KJ, Cross ML, Gopal PK. Enhancement of immunity in the elderly by dietary supplementation with the probiotic Bifidobacterium lactis HN019. Am J Clin Nutr 2001;74:833-9.

103. Greenwald P. Clinical trials in cancer prevention: current results and perspectives for the future. J Nutr 2004; 134:3507S-12S.

104. Gao YT, McLaughlin JK, Blot WJ, Ji BT, Dai Q, Fraumeni JF,Jr. Reduced risk of esophageal cancer associated with green tea consumption. J Natl Cancer Inst 1994;86:855-8.

105. Aktas O, Prozorovski T, Smorodchenko A, Savaskan NE, Lauster R, Kloetzel PM, et al. Green tea epigallocatechin-3-gallate mediates T cellular NF-kappa B inhibition and exerts neuroprotection in autoimmune encephalomyelitis. J Immunol 2004;173:5794-800.

106. Tedeschi E, Menegazzi M, Yao Y, Suzuki H, Forstermann U, Kleinert H. Green tea inhibits human inducible nitric-oxide synthase expression by down-regulating signal transducer and activator of transcription-1alpha activation. Mol Pharmacol 2004;65:111-20.

107. Currier NL, Miller SC. The effect of immunization with killed tumor cells, with/without feeding of Echinacea purpurea in an erythroleukemic mouse model. J Altern Complement Med 2002;8:49-58.

108. Barrett B. Echinacea for upper respiratory tract infection: an evidencebased clinical review. J Fam Pract 1999;48:628-35.

109. Binns SE, Purgina B, Bergeron C, Smith ML, Ball L, Baum BR, et al. Light-mediated antifungal activity of Echinacea extracts. Planta Med 2000;66:241-4.

110. Thompson KD. Antiviral activity of Viracea against acyclovir susceptible and acyclovir resistant strains of herpes simplex virus. Antiviral Res 1998;39:55-61.

111. Larsen MW, Moser C, Hoiby N, Song Z, Kharazmi A. Ginseng modulates the immune response by induction of interleukin-12 production. APMIS 2004;112:369-73.

112. Chang YS, Seo EK, Gyllenhaal C, Block KI. Panax ginseng: a role in cancer therapy?. Integr Cancer Ther 2003;2:13-33.

113. Park EK, Choo MK, Han MJ, Kim DH. Ginsenoside Rh1 possesses antiallergic and anti-inflammatory activities. Int Arch Allergy Immunol 2004;133:113-20.

114. Kim TS, Na K, Choi EM, Chung JY, Hwang JK. Immunomodulating activities of polysaccharides isolated from Panax ginseng. J Med Food 2004;7:1-6.

115. Song Z, Johansen HK, Faber V, Moser C, Kharazmi A, Rygaard J, et al. Ginseng treatment reduces bacterial load and lung pathology in chronic Pseudomonas aeruginosa pneumonia in rats. Antimicrob Agents Chemother 1997;41:961-4.

116. Crittenden RG, Martinez NR, Playne MJ. Synthesis and utilisation of folate by yoghurt starter cultures and probiotic bacteria. Int J Food Microbiol 2003;15:217-22.

Received March 3, 2005; accepted August 26, 2005 


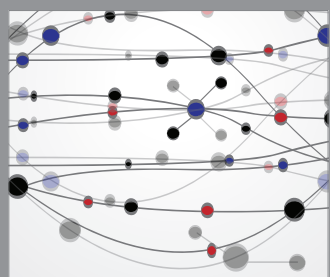

The Scientific World Journal




Gastroenterology

Research and Practice
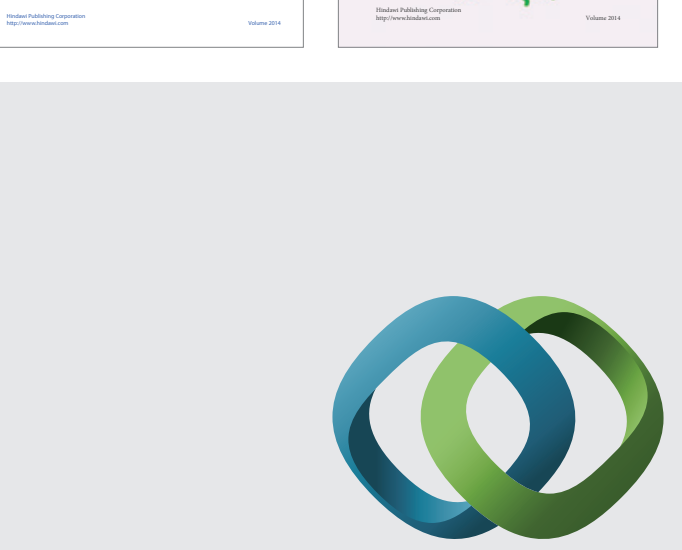

\section{Hindawi}

Submit your manuscripts at

http://www.hindawi.com
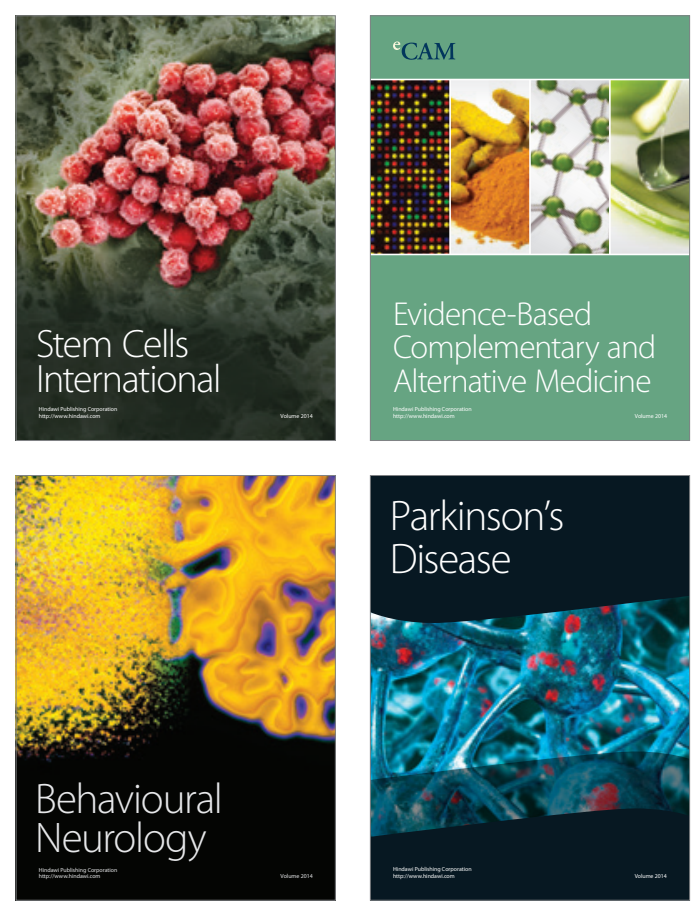

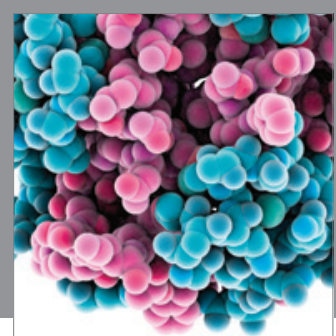

Journal of
Diabetes Research



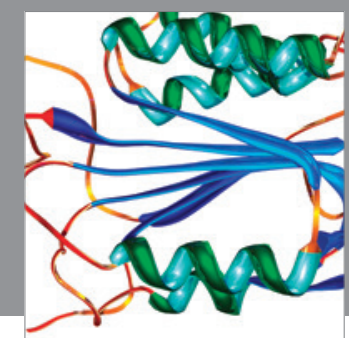

Disease Markers
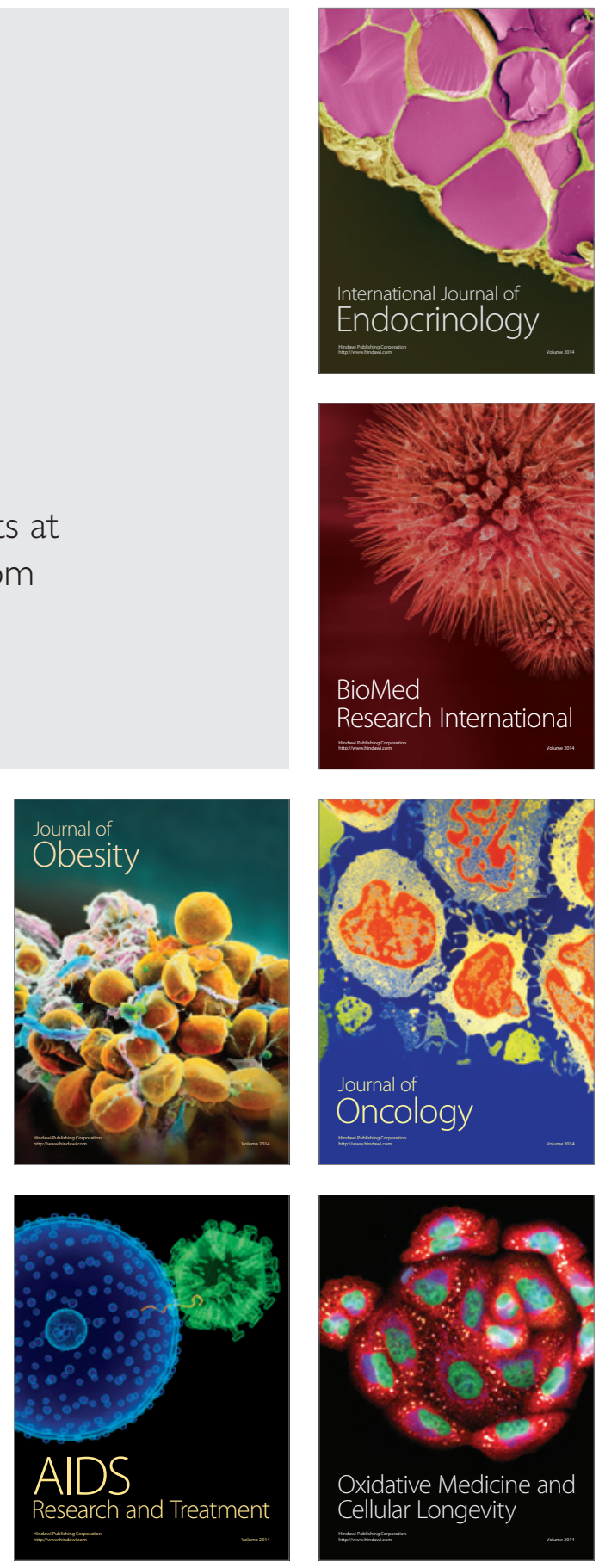